Case Report

\title{
Tender Papule Rising on the Digit: Pacinian Neuroma Should Be Considered in Difierential Diagnosis
}

\author{
Hyun Hee Cho, Jong Soo Hong, Se Young Park, Hyun Sun Park, Soyun Cho, Jong Hee Lee ${ }^{\bowtie}$ \\ Department of Dermatology, Seoul National University, College of Medicine, Boramae Medical Center, Seoul, Korea
}

$\square$ Corresponding author: Jong Hee Lee, MD, PhD, Department of Dermatology, Seoul National University, College of Medicine, Boramae Medical Center, Seoul, Korea. Tel: 82-2-870-2382; Fax : 82-2-831-2826; E-mail: bell711@hanmail.net

( ) Ivyspring International Publisher. This is an open-access article distributed under the terms of the Creative Commons License (http://creativecommons.org/ licenses/by-nc-nd/3.0/). Reproduction is permitted for personal, noncommercial use, provided that the article is in whole, unmodified, and properly cited.

Received: 2011.10.28; Accepted: 2011.11.27; Published: 2011.12.06

\begin{abstract}
Pacinian corpuscles are sensory nerve-end organs located in the deep dermis and subcutaneous tissue of the palms or soles. Pacinian neuroma is an extremely rare feature, defined as hyperplasia or hypertrophy of Pacinian corpuscles. About half of Pacinian neuromas present with point tenderness. There have been a limited number of cases reported around the world. We observed a 45-year-old woman with an 8-month history of a tender whitish papule on her left thumb tip. Histopathologically, an enlarged hypertrophic Pacinian corpuscle in subcutaneous tissue, surrounded by numerous nerve fibers, was found. Herein, we report a case of Pacinian neuroma presenting as a tender papule on a fingertip that was clearly related to repetitive trauma at that site. This case shows that a meticulous history and histological examination can lead to an exact diagnosis and proper treatment.
\end{abstract}

Key words: Pacinian neuroma, repetitive trauma

\section{Introduction}

Pacinian corpuscles are the largest sensory nerve-end organs located in the deep dermis and subcutaneous tissue and function as tactile receptors. They are found in the skin of the palms, soles and genitalia. Macroscopically, they look like fat globules and their density is $3-5 / \mathrm{cm}^{2}$. Histologically, they consist of a central non-myelinated end-terminal axon and surrounding cells and fibrous capsule [1].

Pacinian neuroma is an extremely rare feature characterized by proliferation of normal-sized or enlarged Pacinian corpuscles [2]. There are only a few reported cases of Pacinian neuroma. Herein, we report a case of Pacinian neuroma, presenting as a tender papule on the digit.

\section{Case report}

A 45-year-old woman presented with an 8-month history of a tender papule on her left thumb tip. The lesion had not changed in size or color since then. Her hobby was making tablecloths or house goods with fabrics. She remembered a history of repetitive trauma from a needle when sewing. Physical examination revealed an ill-demarcated approximately 1.5-mm-sized tender whitish papule on the left thumb tip (Fig. 1). There were no inflammatory signs, such as erythema and swelling. She complained of severe pain on touching or grabbing something. She was previously healthy and did not have any other dermatological problems.

For histologic diagnosis, a 2-mm skin biopsy was performed. There were no inflammatory reactions or fibrous scars in the epidermis and dermis. Deep down in the junction of dermis and subcutaneous tissue, a single enlarged Pacinian corpuscle surrounded by numerous nerve fibers was observed (Fig. 2). On the basis of clinical and histological findings, the tender papule on the fingertip was diagnosed as a Pacinian neuroma. Her pain was gone after the skin biopsy. No evidence of recurrence has been observed for 1 year. 


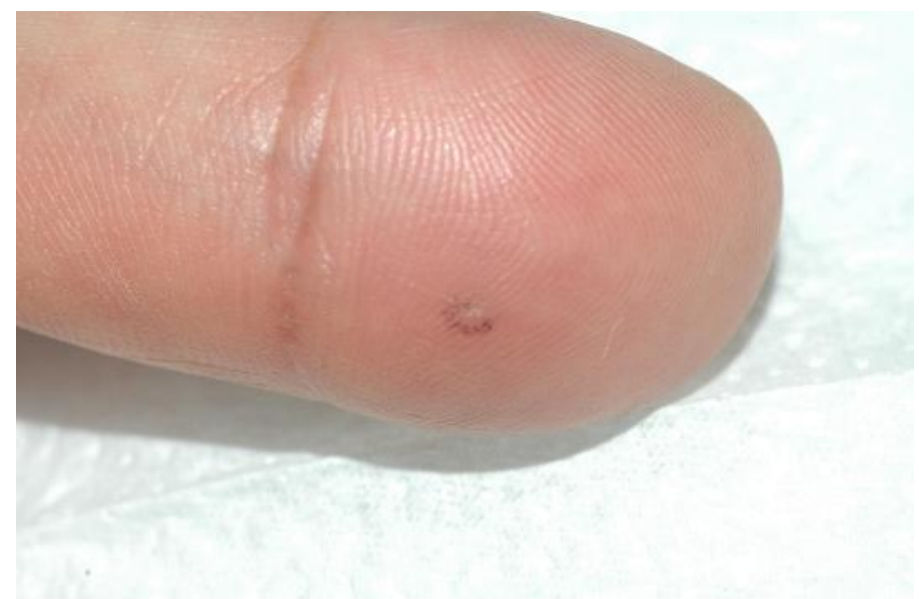

Figure I. There is a tender whitish papule on the left thumb tip.

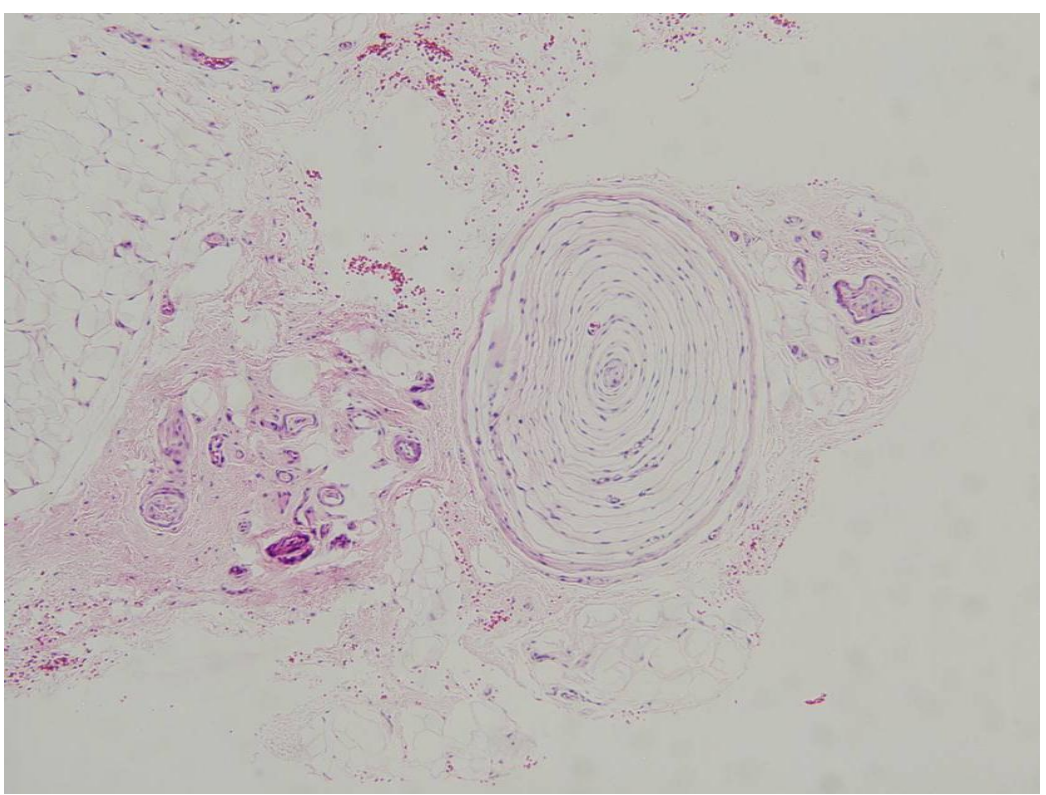

Figure 2. The histopathologic examination shows a single large Pacinian corpuscle in the subcutaneous tissue, surrounded by numerous nerve fibers. (H\&E, XI00)

\section{Discussion}

Pacinian corpuscles are sensory nerve-end organs located in the deep dermis and subcutaneous tissue and they act as tactile receptors [1]. Pacinian neuroma was first described by Prichard and Custer in 1952 [2]. It is a benign lesion characterized by proliferation of normalsized or enlarged Pacinian corpuscles [1,2]. Pacinian neuroma occurs mainly in middle-aged adults and can occur in any finger. However, the index finger and the long finger seem to be more commonly involved. Most patients complain of local tenderness [1].

Histologically, Rhode and Jennings [3] described four types of Pacinian neuroma: A) a single enlarged corpuscle, B) a grape-like structure of normal-sized
Pacinian corpuscles, C) slightly enlarged corpuscles arranged in tandem, and D) hyperplastic Pacinian corpuscles arranged along the entire length of a digital nerve. Later, Michel and Albert [2] considered types $\mathrm{C}$ and $\mathrm{D}$ as the same category. Therefore, $\mathrm{Pa}-$ cinian neuroma is now classified as three types. Based on a review of previously reported cases, the most common type was a cluster of normalsized Pacinian corpuscles (type B) [2]. This case histologically fits into type A Pacinian neuroma.

The etiology and pathogenesis of this rare feature are not clear. However, several reports have proposed that repetitive trauma to the nerves or tendons is a precipitating factor [4-6]. This case had a clear history of repetitive physical trauma and 
strongly supports the hypothesis that recurring trauma plays an important role in inducing Pacinian neuroma.

Benign tumors of non-neural origin, such as hemangioma, fibroma, ganglion cyst, mucoid cyst, and angiolipoma, and of neural origin, including schwannoma and glomus tumor, might be the cause of a tender digital papule. Several autoimmune diseases such as gout, exostosis and arthritis can also present as this condition [7]. A meticulous history and histological examination can lead to the exact diagnosis and proper treatment.

Simple excision is the treatment of choice for $\mathrm{Pa}$ cinian neuroma and, fortunately, a 2-mm punch biopsy provided a cure in this case. When a skin punch biopsy is performed for a tender papule or nodule in the digit, it should be done deeply enough to include subcutaneous tissues.

A limited number of cases of Pacinian neuroma have been reported around the world, suggesting that this condition may be neglected. Recently, work-related conditions are gaining attention and this rare feature appears to be strongly related to work or repetitive trauma. Herein, we report a case of Pacinian neuroma and suggest that Pacinian neuroma should be considered in the clinically differential diagnosis of a tender papule in the digit, especially when a patient has a history of repetitive trauma at the lesion site.

\section{Conflict of Interest}

The authors have declared that no conflict of interest exists.

\section{References}

1. Kenmochi A, Satoh T, Fukuyama K, Yokozeki H. Pacinian neuroma. J Eur Acad Dermatol Venereol. 2006; 20: 1384-5.

2. Reznik M, Thiry A, Fridman V. Painful hyperplasia and hypertrophy of pacinian corpuscles in the hand: report of two cases with immunohistochemical and ultrastructural studies, and a review of the literature. Am J Dermatopathol. 1998; 20: 203-7.

3. Rhode CM, Jennings WD, Jr. Pacinian corpuscle neuroma of digital nerves. South Med J. 1975; 68: 86-9.

4. Lang-Stevenson AI. Induction of hyperplasia and hypertrophy of pacinian corpuscles. Br Med J (Clin Res Ed). 1984; 288: 972-3.

5. Requena L, Sangueza OP. Benign neoplasms with neural differentiation: a review. Am J Dermatopathol. 1995; 17: 75-96.

6. Kumar A, Darby AJ, Kelly CP. Pacinian corpuscles hyperplasia--an uncommon cause of digital pain. Acta Orthop Belg. 2003; 69: 74-6.

7. Kim SW, Jung SN. Glomus tumour within digital nerve: A case report. J Plast Reconstr Aesthet Surg. 2011 Jul;64(7):958-60. 